\title{
SIMILARITY OF FERROSILICON SUBMERGED ARC FURNACES WITH DIFFERENT GEOMETRICAL PARAMETERS
}

\begin{abstract}
In order to determine reasons of unsatisfactory production output regarding one of the 12 MVA furnaces, a comparative analysis with a furnace of higher power that showed a markedly better production output was performed. For comparison of ferrosilicon furnaces with different geometrical parameters and transformer powers, the theory of physical similarity was applied. Geometrical, electrical and thermal parameters of the reaction zones are included in the comparative analysis. For furnaces with different geometrical parameters, it is important to ensure the same temperature conditions of the reaction zones. Due to diverse mechanisms of heat generation, different criteria for determination of thermal and electrical similarity for the upper and lower reaction zones were assumed contrary to other publications. The parameter $c_{3}$ (Westly) was assumed the similarity criterion for the upper furnace zones where heat is generated as a result of resistive heating while the parameter $J_{1}$ (Jaccard) was assumed the similarity criterion for the lower furnace zones where heat is generated due to arc radiation.
\end{abstract}

Keywords: submerged-arc furnace, ferrosilicon, similarity $k, c_{3}, J_{1}$

\section{Introduction}

Ferrosilicon smelting is a continuous process carried out in submerged arc furnaces with Søderberg self-baking electrodes that are immersed in the charge material [1-2]. Adequately granulated raw materials are charged into the furnace from its top as a mixture consisting of: quartzite; carbon reducers - pea coal, pea coke and wood chips; iron-bearing material - mill scale or steel chips. Heat, necessary for highly endothermic silica reduction by carbon, is generated directly in the charge as a result of current flow (resistive heating) or due to arc heating in the chambers located near the electrode tips. Periodically at equal time intervals, molten metal is tapped into the ladle through one of the tap holes located near the furnace hearth. The apparently simple technology of ferrosilicon smelting involves many correlating physicochemical, thermal and electrical processes. Being an electrothermal device, the submerged arc furnace intended for ferrosilicon smelting should provide proper temperature conditions for chemical reactions. However, there is a frequently misconception that to get a predetermined furnace capacity simply to bring defined amount of electricity arising from the heat balance of the process. This follows that the submerged arc furnace is considered only as the high power electricity receiver.

However, there exists a wrong opinion among some practitioners that expected furnace efficiency can be simply guaranteed by delivery of specified amounts of electrical energy resulting from the thermal balance of the process and the submerged arc furnace is considered only as a high power electric energy receiver. The main idea of this paper was investigation aimed at determining the reasons of unsatisfactory production output one of the 12 MVA furnaces manufacturing ferrosilicon FeSi65 or FeSi75. It should be noted that for slag processes (FeSiMn, FeSiCr), the same furnace yielded a fairly good output. On the improvement of 12 MVA furnace production did not affect its modernization carried out during the general overhaul. The high current track was modernized and improved its symmetrization [4], and upgraded the burdening charge system, as well as registration and visualization of measurement data system. Despite this, not reached the target output resulting from the power transformer $12 \mathrm{MVA}$, nor improvement of technical and economic process of the ferrosilicon smelting. In order to determine the reasons of unsatisfactory production output regarding the investigated 12 MVA furnace, a comparative analysis with a 20 MVA furnace (showing a markedly better production output) was performed. For comparison of ferrosilicon furnaces with different geometrical parameters and transformer powers, the theory of physical similarity was applied [3]. Geometrical, electrical and thermal parameters of the reaction zones as well as the structure of raw material consumption and other conditions are all included in the comparative analysis.

\footnotetext{
* SILESIAN UNIVERSITY OF TECHNOLOGY, FACULTY OF MATERIALS ENGINEERING AND METALLURGY, KATOWICE, POLAND

** SILESIAN UNIVERSITY OF TECHNOLOGY, INSTITUE OF METALS TECHNOLOGY, KATOWICE, POLAND

\# Corresponding author: boleslaw.machulec@polsl.pl
} 


\section{Physical similarities of ferrosilicon furnaces}

Electrodes immersed in the charge that deliver electrical current to the working space are one of the most important structural components of the ferrosilicon furnace working space. The electrodes form the reaction zones, the size of which depends mainly on their diameter $d$. The reaction zones are areas where the current flows, heat is generated and continuous charge movement occurs. Considering the mechanism of heat generation in physicochemical and electrical models of the ferrosilicon furnace bath, there are two zones: the charge zone (zone 1) where heat is generated through resistive heating and the inner part of the gas chamber of the arc (zone 2) where heat is generated due to arc radiation [1-2]. Regarding similar physicochemical conditions of the process in furnaces with different geometrical parameters, temperature conditions of the reaction zones should be primarily taken into account so as the temperature scales meet the following:

$$
k_{T}=T / T^{\prime}=1
$$

where: $T, T^{\prime}$ - temperatures of reaction zones of furnaces with different geometrical parameters.

Ferrosilicon smelting is an almost non-slag process; therefore, with small amounts of the liquid phase, convective heat transfer is limited and the thermal conductivity in the furnace is low. The reason for this is the lack of conditions to equalization of temperatures. Therefore, the temperature at specific points of the reaction zones where heat is generated as a result of resistive heating (zone 1) is mostly determined by volume power density $q_{V}$ and thermodynamic processes related to the course of chemical reactions. Different conditions are observed in zones where heat is generated as a result of arc heating. In the arc gas chambers, heat transfer is mainly driven by radiation and convection [9]. Consequently, to satisfy the condition (1), different thermal similarity criteria for the upper and lower ferrosilicon furnace zones are required:

Zone 1:

$$
q_{V}=\text { const }
$$

Zone 2:

$$
q_{S}=\text { const }
$$

where:

$q_{V}-$ volume power density, $\mathrm{MW} / \mathrm{m}^{3}$,

$q_{S}-$ power density at the electrode cross-section, $\mathrm{MW} / \mathrm{m}^{2}$.

In almost all publications on ferrosilicon smelting in physicochemical and electrical models, electrical and thermal similarity criteria $k, c_{3}$ by Andreae and Strunski-Westly are applied $[1,2,6,7]$ :

$$
\begin{gathered}
k=R \pi d k, \Omega \mathrm{m} \\
c_{3}=I \cdot P_{u}^{-2 / 3}, 10^{-1} A \cdot W^{-2 / 3},\left(\mathrm{kA} \cdot \mathrm{MW}^{-2 / 3}\right)
\end{gathered}
$$

where:

$R$ - furnace bath resistance, $10^{-3} \Omega,(\mathrm{m} \Omega) ;$

$d$ - electrode diameter, $\mathrm{m}$,
$P_{u}-$ furnace useful active power, MW, $P u=P_{a} \cdot \eta$,

$P_{a}-$ furnace active power, MW,

$\eta$ - a coefficient for the furnace electrical efficiency related to loss due to high current track resistance, $\eta \cong 0.90 \div 0.95[7]$,

$I$ - phase current of the electrodes, $\mathrm{kA}$,

$\pi$ - number, $\pi \approx 3.14$.

Formula (5), known as the Westly formula [6] in many publications, was earlier theoretically determined by Mikulinski (1966) based on the similarity theory and dimensional analysis [8] as well as by Strunski based on laboratory testing using the electrolytic model of the furnace [7]. The basic geometrical parameter of the submerged arc furnace is the electrode diameter $d$ which, like other geometrical parameters, should be adjusted to the power of transformer. Considering formulas (1) and (2), the geometrical parameters of furnaces can be determined as follows:

$$
d=A_{1} \cdot P_{a}^{1 / 3}, \mathrm{~m}
$$

where: $A_{1}-$ constant, $\mathrm{m} \cdot \mathrm{MW}^{-1 / 3}$.

Analogically to (6), empirical relationships in the form of regression equations can be found in the monograph [2]:

$$
\left.\begin{array}{l}
d=0.48344 \cdot P_{a}^{0.3257}, \mathrm{~m} \\
d=0.42342 \cdot S_{T r}^{0.3371}, \mathrm{~m}
\end{array}\right\}
$$

where: $S_{T r}$ - nominal power of the transformer, MV A.

Assuming the electrode diameter $d$ as the base value, the other geometrical parameters of the furnace $L$ can be determined, using the geometrical similarity constants $k_{L}$ [7]:

$$
L=k_{L} \cdot d
$$

The Strunski model and formulas (4), (5) neglect meaningful differences in electrical properties as well as mechanisms of heat generation in the upper and lower zones of the ferrosilicon furnace. In the gas chambers, heat flux is mostly generated as a result of arc radiation and, to a lesser extent, of convection. Consequently, according to the Newton's law [9], it is proportional to the heat-emitting surface. Thus, the assumption of surface power density (3) as the criterion of thermal and temperature similarity in the arc chambers is justified. For determination of the thermal similarity criteria of the arc gas chamber, Luis R. Jaccard's concept is useful [5] which assumes that the phase active power of the furnace $P_{1 a}$ should be proportional to the surface power density at the arc chamber cross-section, which is equivalent to (2). Based on the dimensional analysis, Luis R. Jaccard proposed the formula [5]:

$$
U=J_{1} \cdot d \sqrt{l_{p}} \cdot P_{1 a}^{-1 / 4}, \mathrm{~V}
$$

where:

$$
\begin{aligned}
U & - \text { phase voltage, } \mathrm{V}, \\
l_{p} & - \text { electrode spacing, } \mathrm{m}, \\
P_{1 a} & - \text { phase active power, } \mathrm{W}, \\
J_{1} & - \text { similarity constant, } \mathrm{V} \cdot \mathrm{m}^{-3 / 2} \cdot \mathrm{W}^{4} .
\end{aligned}
$$


The parameter $J_{1}$ determines thermal and electrical similarity of the gas chambers while the parameters $k, c_{3}$ characterize thermal and electrical conditions of the upper furnace areas (zone 1) where heat is generated in the charge as a result of resistive heating. Due to different electrical properties of the zones 1 and 2 as well as diverse mechanisms of heat generation, differences in current characteristics for the upper and lower zones of the ferrosilicon furnace are observed. Current characteristics for the upper furnace zones can be determined by means of the Wesley formula (5) as follows:

$$
P_{a}=\frac{1}{\eta} \cdot\left(\frac{I}{c_{3}}\right)^{3 / 2}, \mathrm{MW}
$$

Similarly, assuming load symmetrisation, current characteristics for the lower furnace areas (zone 2) can be determined with the use of Luis R. Jaccard formula (9) as follows:

$$
I \cong \frac{P_{1 a}}{U}=\left(\frac{P_{a}}{3}\right)^{5 / 4} /\left(J_{1} \cdot d \cdot \sqrt{l_{p}}\right), \mathrm{kA}
$$

and

$$
P_{a}=3 \cdot\left(I \cdot J_{1} \cdot d \cdot \sqrt{l_{p}}\right)^{4 / 5}, \mathrm{MW}
$$

\section{Comparative investigations of the furnaces}

In order to determine criterion values for the investigated furnaces, technical data for the FeSi75 ferrosilicon smelting process were applied. The model 20 MVA ferrosilicon furnace is characterized by a stable production output at the level below $8500 \mathrm{kWh} / \mathrm{t}$. During periods of good performance, this furnace shows the average daily electrical energy consumption below $8200 \mathrm{kWh} / \mathrm{t}$. Despite the use of raw materials demonstrating comparable parameters, the best daily indexes of electricity consumption for the investigated 12 MVA furnace were above $8800 \mathrm{kWh} / \mathrm{t}$. The $20 \mathrm{MVA}$ is an open furnace with three electrodes, diameter $d=1.2 \mathrm{~m}$, located at the vertices of equilateral triangle. It is equipped with an autotransformer with controlled secondary voltages, three one-phase 6.67 MVA furnace transformers and an unsymmetrical, bifilar high current track. The autotransformer is powered from a $110 / 6 \mathrm{kV}$ electrical distribution unit and has 25 taps to change secondary voltages of transformers, under load conditions, within $100 \div 200 \mathrm{~V}$. The 12 MVA is a semi-closed furnace but its equipment is comparable to that of the 20 MVA furnace. The diameter of electrodes is $d=0.9$ and the furnace is equipped with an autotransformer with a tap changer to control the voltage under load conditions, a three-phase transformer and a bifilar, unsymmetrical high current track. The autotransformer has 19 taps to change secondary voltage of the transformer within 109-170 V. It should be noted that the electrode diameter $d=0.9 \mathrm{~m}$ of the $12 \mathrm{MVA}$ furnace is too small for the transformer power. The formula (6) indicates that for the nominal power $S=12 \mathrm{MVA}$, the electrode diameter should be $d \cong 0.98 \mathrm{~m}$. To determine parameters that characterize thermal and electrical similarity of the reaction zones $\left(k, c_{3}, J_{1}\right)$, averaged technical parameteres for adequatly selected daily periods were applied. The days when the investigated furnaces yielded the best production output were selected for the analysis. Concerning the 20 MVA furnace, these were days when the average electricity consumption index was not higher than $8.150 \mathrm{MWh} / \mathrm{t}$. For the $12 \mathrm{MVA}$, the days when the unit electricity index was below $8.900 \mathrm{MWh} / \mathrm{t}$ were selected. Comparative data regarding the FeSi75 ferrosilicon smelting process in the investigated furnaces are listed in Table 1. The data refer to basic geometrical parameters of the furnaces, averaged electrical parameters, parameters that characterize thermal and electrical similarity of the reaction zones $\left(k, c_{3}, J_{1}\right)$ and production results. A high value of the parameter $k=6.47 \cdot 10^{-3} \Omega \mathrm{m}$ for the investigated 12 MVA furnace should be noted compared with the 20 MVA furnace, which suggests resistance $R$ of the 12 MVA furnace being too high. It results in a shallow location of the electrodes in the charge and unfavourable conditions for the electric arc burning. The reason is incorrect selection of the electrical parameters of the furnace, particularly current load of the electrodes being too small. In addition, temperature conditions of the process in the 12 MVA furnace are deteriorated by the active power that is too high for the electrode diameter $d$. The volume power density in the reaction zones is $P_{1 u} / d^{3}$ $=3.452 \mathrm{MW} / \mathrm{m}^{3}$ while for the model furnace, it accounts for $3.029 \mathrm{MW} / \mathrm{m}^{3}$.

TABLE 1

\begin{tabular}{|c|c|c|c|}
\hline Parameter & Unit & $20 \mathrm{MVA}$ & 12 MVA \\
\hline 1 & 2 & 3 & 4 \\
\hline \multicolumn{4}{|l|}{ Geometruc parameters } \\
\hline Electrode diameter, $d$ & $\mathrm{~m}$ & 1,2 & 0,9 \\
\hline Electrode spacing, $l_{p}$ & $\mathrm{~m}$ & 2,685 & 2,044 \\
\hline \multicolumn{4}{|l|}{ Electrical parameters } \\
\hline Active power, $P_{a}$ & MW & 16,669 & 7,839 \\
\hline One electrode active power $P_{1 a}=P_{a} / 3$ & MW & 5,556 & 2,613 \\
\hline Power factor, $\cos \phi$ & & 0,849 & 0,924 \\
\hline Electrical efficiency, $\quad \eta$ & & 0,940 & 0,970 \\
\hline Useful active power, $\quad P_{u}=P_{a} \cdot \eta$ & MW & 14,158 & 7,247 \\
\hline Useful active power, $\quad P_{1 u}=P_{u} / 3$ & MW & 4,719 & 2,416 \\
\hline Phase voltage, $\quad U$ & v & 88,36 & 79,00 \\
\hline Phase current, I & $\mathrm{kA}$ & 62,94 & 33,08 \\
\hline Daily energy consumption & $\mathrm{MWh}$ & 400,07 & 188,14 \\
\hline \multicolumn{4}{|l|}{ Production results } \\
\hline Daily metal output (pure), w & $t / 24 h$ & 49,519 & 21,276 \\
\hline Volume performance index, $\mathrm{w} /\left(3 \cdot 24 \cdot d^{3}\right)$ & $t /\left(m^{3} h\right)$ & 0,398 & 0,405 \\
\hline Electricity consumption index, $E$ & $\mathrm{MWh} / \mathrm{t}$ & 8,079 & 8,843 \\
\hline \multicolumn{4}{|l|}{ Similarity criteria } \\
\hline Current density, $j=4 \cdot I /\left(\pi \cdot d^{2}\right)$ & $10^{4} \mathrm{~A} / \mathrm{m}^{2}$ & 5,565 & 5,201 \\
\hline Volume power density, $\quad P_{1 u} / d^{3}$ & $\mathrm{MW} / \mathrm{m}^{3}$ & 2,731 & 3,314 \\
\hline Furnace resistance, $\quad R=P_{1 u} / I^{2}$ & $10^{-3} \Omega$ & 1,191 & 2,207 \\
\hline Parameter Andrea, $\quad k=R \cdot \pi \cdot d$ & $10^{-3} \Omega \mathrm{m}$ & 4,491 & 6,240 \\
\hline Parameter Westly, $\quad c_{3}=I \cdot P_{u}^{-2 / 3}$ & $10^{-1} \mathrm{AW}^{-2 / 3}$ & 10,05 & 8,56 \\
\hline Parametr*, $J_{1}=U \cdot P_{1 a}{ }^{0,25} /\left(d \cdot l^{0,5}\right)$ & $10^{3,75} V W^{1 / 4} / m^{1,5}$ & 0,388 & 0,439 \\
\hline \multicolumn{4}{|l|}{ Raw materials consumption: } \\
\hline Daily quartzite consumption, $\mathrm{Q}$ & $\mathrm{kg} / 24 \mathrm{~h}$ & 85736 & 44997 \\
\hline Quartzite consumption index & $\mathrm{kg} / \mathrm{t}$ & 1731,4 & 2114,9 \\
\hline Quatrzite consumption per $1 \mathrm{MWh}$ & $\mathrm{kg} / \mathrm{MWh}$ & 214,3 & 239,2 \\
\hline Quartzite stream index, $Q /\left(3 * 24 * d^{3}\right)$ & $\mathrm{kg} /\left(\mathrm{m}^{3} \mathrm{~h}\right)$ & 689,1 & 857,3 \\
\hline Si yield & $\%$ & 94,24 & 77,15 \\
\hline
\end{tabular}

Investigated $12 \mathrm{MVA}$ and 20 MVA furnaces: comparative data for ferrosilicon FeSi75 production 
This unfavourably affects conditions for gaseous SiOcondensation in the process of silica reduction by carbon $[1,2]$ and results in a very low yield of $\mathrm{Si}(77.0 \%)$ as well as disorders of the process related to $\mathrm{SiC}$ deposition in the furnace due to silica deficiency. The electrode diameter that is too small prevents from the use of full 12 MVA transformer power. Therefore, considering the criteria of thermal and electrical similarity of the reaction zones $\left(k, c_{3}, J_{1}\right)$ with regard to the model $20 \mathrm{MVA}$ furnace, the electrical parameters of the 12 MVA furnace were adjusted. The furnace active power was reduced from 7.8 MW to approx. 7.1 MW and the electrode current load was increased from $33 \mathrm{kA}$ to $35.5 \mathrm{kA}$. Using the formulas (10) and (12), current characteristics for the upper and lower zones of the $12 \mathrm{MVA}$ furnace before and after the change of electrical parameters are presented in Fig. 1. These characteristics are not the same due to different mechanisms of heat generation. Proper balancing of heat fluxes $q_{1}, q_{2}$, generated as a result of current flow due to resistance and arc heating, is seen at the intersection point of both characteristics (Fig. 1). This point corresponds to optimal location of electrodes in the furnace and minimisation of raw material and energy consumption indexes. The change of furnace electrical parameters favourably affected its production output and gradual improvement of the technical and economic indicators regarding the process of ferrosilicon smelting (Fig. 2).

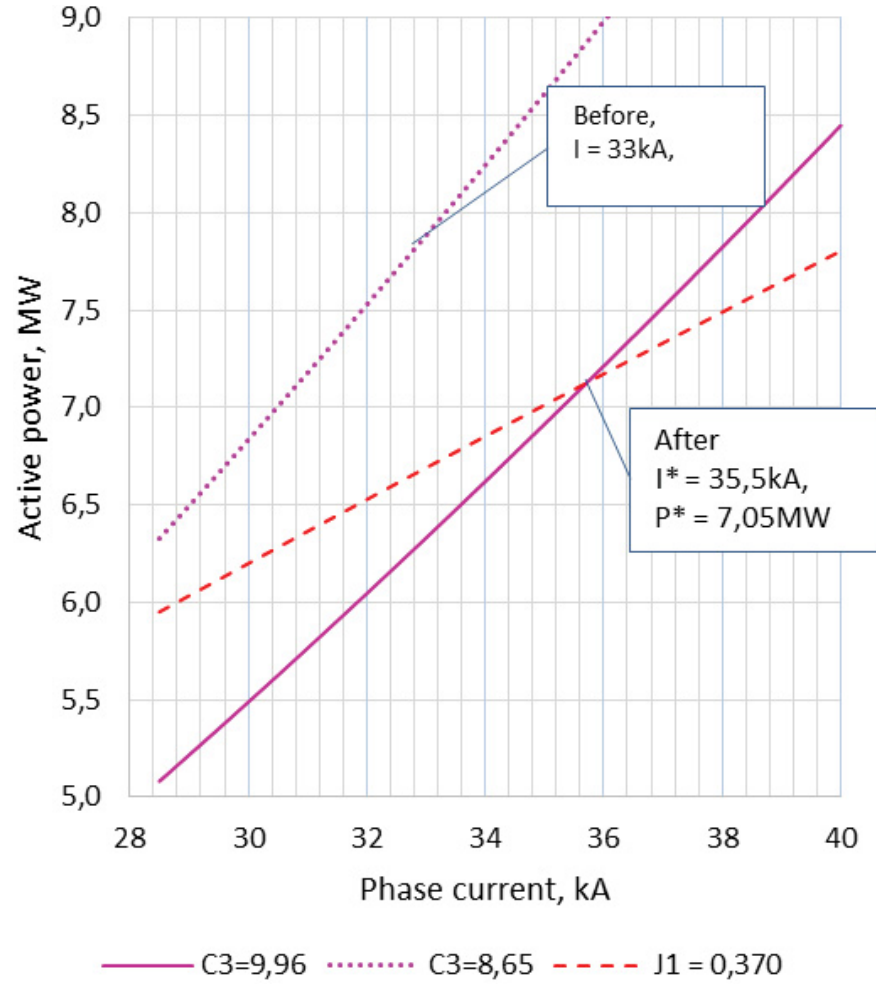

Fig. 1. Current characteristics of the 12 MVA furnace before and after the change of electrical parameters
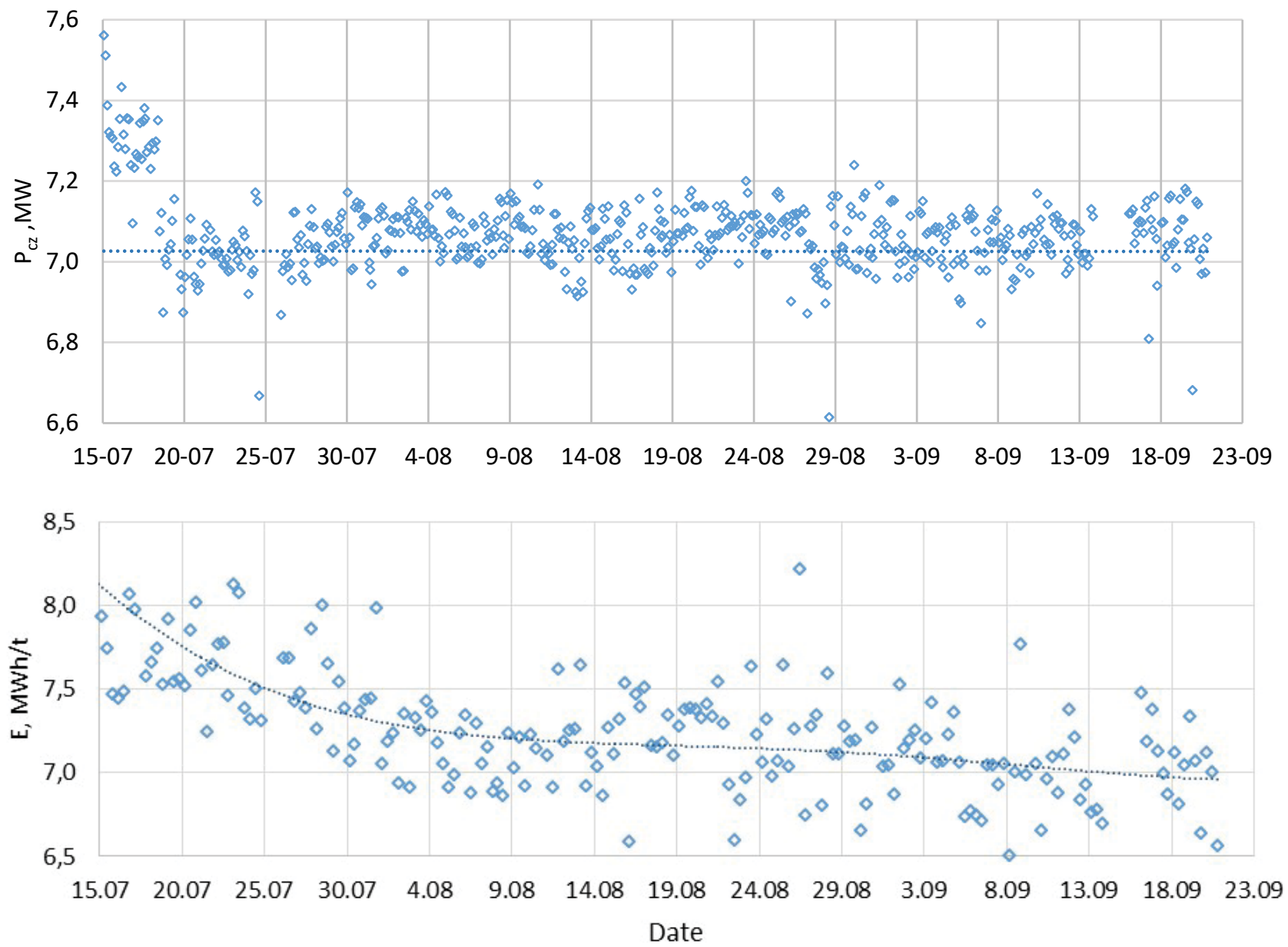

Fig. 2. Effects of the change in the electrical parameters of the 12 MVA furnace dated 18 Jul 2016 on improvement of the electricity consumption index regarding the FeSi65 ferrosilicon smelting process 


\section{Summary}

For given geometrical parameters of the submerged arc furnace, strictly specified electrical parameters correspond to optimal temperature conditions in the reaction zones during ferrosilicon smelting. These parameters are determined at the intersection point of current characteristics for the upper and lower reaction zones, which refers to optimal location of the electrodes in the furnace as well as minimisation of raw material and energy consumption indexes. While specifying current characteristics for the upper zones of the furnace where heat is directly generated in the charge due to resistive heating, a useful parameter is $c_{3}$ (Westly) while for current characteristics of the lower furnace zone where heat is generated as a result of arc radiation, the parameter $J_{1}$ (Jaccard) is recommended. The $c_{3}$ and $J_{1}$ parameters characterize similarity of the thermal and electrical parameters of the reaction zones. For furnaces with different geometrical parameters, the $c_{3}$ and $J_{1}$ values should be comparable to those for the model furnace that shows good production output.

\section{Acknowledgements}

This work was supported by Association of Graduates of the Faculty of Metallurgy and Materials Engineering of Silesian University of Technology, Poland.

\section{REFERENCES}

[1] A.J. Schei, K. Tuset, H. Tveit, Production of High Silicon Alloys, (1998), Trondheim.

[2] V.L. Zubov, M.I. Gasik, Electrometallurgy of ferrosilicon.Physical Chemistry and Technology, 2002, Dnepropetrovsk.

[3] J. Rychlewski, Wymiary i podobieństwo, 1991,Warszawa.

[4] B. Baron, B. Machulec, J. Przegędza, Influence of change inreactance of high current circuit on furnace resistance and temperature distribution in ferrosilicon melting process, Research in Electrotechnology and Applied Informatics, Conference Proceedings, Katowice-Kraków, 131-137 (2005), https://www.researchgate. net/publication/300107920, 2016-09-23

[5] J.L. Ricardo, Submerged arc Furnaces - Optimal Electrical Parameters, http://www.researchgate.net/publication/267722524, 2016-09-23.

[6] J. Westly, Critical parameters in design and operation of the submerged arc furnaces, Electric Furnace Conf. Proc, 47-57 (1976).

[7] B.M. Struński, Rudnotermczeskie Pławilne pieczi, Moskwa (1972).

[8] A.S. Mikulinski, Procesy rudnoi elektrotermii, Moskwa (1966).

[9] J. Tomeczek, Termodynamika, (1999), Gliwice. 